\title{
Financial Management Early-Warning Mechanism Construction and Decision Analysis Research Based on Wireless Sensor Network and Data Mining
}

\author{
Zeyuan Chang ${ }^{1}$ and Heran Yang $\mathbb{D}^{2}$ \\ ${ }^{1}$ Business School, Shandong Normal University, Jinan, 250014 Shandong, China \\ ${ }^{2}$ D'Amore-Mckim School of Business, Northeastern University, Boston, 02115 MA, USA \\ Correspondence should be addressed to Heran Yang; yang.her@northeastern.edu
}

Received 29 October 2021; Accepted 1 December 2021; Published 21 December 2021

Academic Editor: Alireza Souri

Copyright (c) 2021 Zeyuan Chang and Heran Yang. This is an open access article distributed under the Creative Commons Attribution License, which permits unrestricted use, distribution, and reproduction in any medium, provided the original work is properly cited.

\begin{abstract}
With the gradual and complete establishment of the current socialist legal market economy management system with Chinese characteristics and the continuous investment in deepening system reform and continuous improvement in the later period, the social financial industry and corporate financial management have gradually increased their risk awareness of corporate financial management. This paper deeply analyzes and studies the statistical methods of financial data-related legal rule interactive mining and proposes a new improved statistical algorithm of financial-related legal rules, which greatly improves the work efficiency of financial data interactive mining. At the same time, a multilevel analysis model based on the concept of corporate financial crisis risk assessment and a corporate financial crisis risk early-warning analysis model for decision-making risk evaluation are proposed. Finally, it can be determined how to choose more internationally representative corporate financial management risk analysis indicators, which have more objectivity and practical application significance than traditional analysis methods. Finally, it is concluded that the accuracy of this model is better than that of other models. The accuracy rate of financial crisis prediction reached $62.35 \%$.
\end{abstract}

\section{Introduction}

In August 2007, the Subprime Crisis broke out again in the United States. The global international financial market was turbulent. A large number of subprime mortgage asset loan management institutions were forced to go bankrupt, and investment funds were forced to go bankrupt and close. From the US subprime mortgage and US debt financial crisis to the current global European subprime mortgage financial crisis, the world's major international financial rating markets have failed to give clear instructions for industry management in advance by the world's three major international rating industry management agencies. Risk speculation early-warning rating behavior attitude is disappointed, and the current effective international rating industry management procedures, methods, effective evaluation management model, and construction system of the current major international rating industry management agencies have strongly questioned the degree. It is generally believed that we should still be concerned about the potential major international conflicts of interest and risk impacts in the industry in the next few years and the excessive emphasis on large-scale rating behavior by the three major international rating industry management agencies. Competitors in the monopolistic market believe that sound rating reforms should be carried out first. The enlightenment from the US subprime mortgage crisis and the European sovereign debt crisis is that international investment banks and international rating agencies are unreliable, and China needs to establish its own financial risk crisis early-warning system.

With the rapid development of wireless measurement sensor-related networks and applied data mining-related technologies, related network theories and technical applications are becoming more mature. The fusion of application 
databases plays a very important role in the research of wireless measurement sensor-related networks. The main function is to save the data energy of the entire related network, enhance the analysis accuracy of the related data that needs to be collected, and greatly improve the network collection of related data, three main aspects of work efficiency. The application of data fusion mining technology does not require too complicated traditional mathematical analysis theory or reasoning. As long as you pass the screening of the relevant database, you can quickly discover some hidden risk characteristics in the relevant database, and you do not need to manually set the assumptions below. It is necessary to manually adjust the hypothetical threshold value to be able to accurately find the risk rules in the relevant data collection. Therefore, this data mining technology method is widely used in a company's timely analysis of financial crisis risks and other crisis hazard early warnings, to establish a dynamic analysis of corporate financial crisis risks and other crisis hazard early-warning management models and find a company with the new rules of high trust, timely analysis, and early warning of important financial crisis risks and other crisis hazards that an enterprise may have become the main academic research topic of this research topic.

In today's era of information flooding, there have been constant scientific researchers conducting in-depth research on financial management early-warning institutions and decision-making analysis. Buczak and Guven, through an in-depth study of corporate financial management risks, made an in-depth discussion on how to effectively strengthen the financial management risk management of large-scale enterprises. Under the comprehensive analysis of macroqualitative and substantive quantitative analysis, it is the main reason why the financial management risk management of large-scale enterprises in our country is formed. On the basis of Kaishan's research to establish an earlywarning system for corporate financial risks, improve the internal control mechanism of the enterprise, and make appropriate risk decisions, this research is not thorough enough [1]. Helma et al. are mainly represented by the annual $\mathrm{z}$-calculation analysis and model analysis. The multiyear discriminant analysis model of corporate financial data risk monitoring and early warning is based on the annual statistics and calculation analysis of the financial data of a listed company in a specific time period. From the perspective of economic practical research on the internal financial decision-making of small and medium-sized stocks and nonlisted companies, it is proposed that a set of unit multivariable corporate financial risk early-warning multianalysis models suitable for the economic characteristics of listed companies should be established to effectively reduce the daily operation of listed companies. There are risks in internal decision-making, but this research method is outdated in today's era [2]. Duivesteijn et al. use university management financial accounting as an analysis to review the past, control the current situation in the future, and plan the basic financial concepts of the future. From the four aspects of university financial management planning, financial management organization, financial risk control, and financial risk evalu- ation that universities need to promote. It analyzes the main financial management risks of higher vocational colleges at each stage, studies and proposes the establishment of a financial management risk monitoring and early-warning evaluation mechanism at each stage of the university, and constructs an implementation plan. This risk early-warning plan is obviously insufficient targeted [3]. Adeniyi et al. analyze and establish the collection of information volume of the financial risk early-warning system of human-based financial capital enterprises based on the theory of using human-based financial capital resource structure and the law of coupling use between various corporate financial cost resources and noncorporate financial cost resources. Through transmission forecasting mechanism, basic organization and management mechanism of human-based financial capital enterprise financial risk early-warning system, and the use of human-based financial capital and other financial enterprise risk information early-warning information processing and forecasting mechanism, a financial risk early-warning mechanism for various enterprises using human financial capital has been constructed. Obviously, this mechanism is not comprehensive enough for financial risk early-warning reports [4]. Wang's research focuses on how to strengthen and improve the hospital's internal basic-level integrated financial and internal accounting risk management. It is under the in-depth study, discussion, research, and analysis to strengthen the hospital's internal basic-level financial management, generate internal risks and the reasons for the necessity and prerequisites, and accelerate to study, establish, improve, and strengthen the internal risk statistical monitoring, evaluation, early warning, and financial evaluation risk management mechanism and working methods of the hospital's internal primary financial management. Evaluate the basis of financial control risk management, complete and improve the hospital's internal integrated financial risk monitoring and earlywarning evaluation management mechanism, establish and improve the internal risk monitoring and early-warning evaluation index system of the hospital's internal primary financial management and other related policies and measures to comprehensively and effectively avoid the hospital's financial operations of all kinds of risks, and grasp the initiative of the hospital's financial work, and the experimental basis of this research is obviously not sufficient [5]. Lin et al. define the company's net cash inflows generated during the current period of operating business activities as positive or negative, and a risky company whose cash flow and other cash inflow equivalents continue to increase during the operating period is positive or negative can be defined as a long-term financial crisis. At the same time, through the analysis of the internal and external factors driving influencing factors that these companies may fall into the long-term financial crisis, and on this basis, the basic theoretical design framework of the enterprise financial crisis risk earlywarning management system is established. This theoretical framework is difficult to match the actual situation. It complies with [6]. Purves et al., based on the comprehensive analysis of comprehensive financial indicators, introduced comprehensive governance financial structure analysis 
factors. The unsupervised wireless network model in government management assisted the abnormal warning information to carry out a comprehensive upgrade to the earlywarning system, and the joint $5 \mathrm{~g}$ made the early-warning system response time faster; this analysis does not combine Internet information fusion, making this research method lagging behind [7].

This paper mainly proposes an interactive improved data mining analysis algorithm for data association structure rules and proposes an interactive data mining analysis algorithm for data association analysis rules based on optimized Hash association structure called HIUA, which is mainly for data support or threshold changes. This mining algorithm (MA) reimproves the data pruning process of the original IUA, MA, and reimproves the efficiency of the algorithm during normal operation by optimizing the Hash association structure. This paper adopts a complementary combination of fuzzy calibration processing model and fuzzy inference analysis model to process data from multiple sensors and at the same time to ensure the accuracy and reliability of the data under different risk detection data conditions. The fuzzy calibration processing model is mainly used to analyze how many sensors to realize automatic adjustment of datarelated information under the same financial index. By interactively mining the association rules between all corporate financial indicators, we can finally determine how to choose a more internationally representative financial enterprise risk analysis indicator, which is more objective and practical than traditional analysis methods. Therefore, the earlywarning system proposed in this article has a good operating effect for financial companies and can achieve the effect of crisis prevention and the ability to make decisions.

\section{Principle and Theory Overview}

2.1. Overview of Wireless Sensor Networks. With the continuous progress of current modern microelectronic processing software technology, computer network processing technology, and other modern real-time wireless communication network information processing technology, low-tech cost and low-power multifunctional wireless network sensor monitoring technology has been rapidly developed. Widespread application and development have made it possible to integrate wireless monitoring object information for real-time monitoring and collection, data processing, and real-time wireless communication between man and machine and other important monitoring functions in a small cost volume. The connection relationship between sensors, perceptron and communication detection objects, and information detection and observers constitute three basic technical elements of the wireless science physics natural sensor information science technology network, the perception communication object before detection, and the detection object after processing. The connection of communication perception objects after data and communication connection is the operation of three important technical components of the wireless science physics natural sensor information science and technology network. The node itself is not only the network collector and transmission sender of the collected information, but also the network router of the collected information. The collected information data reaches multiple gateways through multiple routing nodes $[8,9]$. The sink node is a special network node that can communicate with the gateway monitoring data center through the Internet, mobile communication wireless network, satellite, etc. The wireless data sensor node network structure diagram is shown in Figure 1.

Wireless photoelectric network sensor technology application power network, in addition to the common important basic characteristics that should have many irreversible mobility, disconnection, power system management capabilities, and technical limitations, it also believes that it should have many other distinctive features.

2.1.1. Dynamic Network. The relative node of the wireless network in a sensor relative node acquisition network is very likely to be randomly and automatically deployed directly. At the same time, a wireless battery relative node automatically provides a certain amount of energy in the relative node network. When the energy system of the relative node cannot be used up automatically or the energy cannot be automatically detected when the environment in the wireless network changes, it will directly and automatically cause the energy system in the relative node to fail or the wireless network failure, and the relative node cannot automatically collect normally. The detected data becomes the relative node in the process of death of the wireless network. At this time, a relative topological system structure of a wireless network is very likely to change. Therefore, a wireless network itself is a very safe and dynamic relative node collection network in a sensor relative node collection network $[10,11]$.

2.1.2. Self-Organizing Network. The location of the topology of the wireless network sensor system network terminal nodes cannot be accurately set in advance, and the relationship between neighboring nodes and network neighbors between nodes cannot be accurately known in advance. These important network nodes are automatic and integrated. Organizations quickly adapt and combine to form a new node wireless network. This article has also mentioned in detail the important node terminal topology and network structure of the terminal network of the wireless network node sensor system which are usually dynamically changed, so due to the automatic and comprehensive organization of the wireless network node sensor system node terminal network, the nature also makes the need to be more conducive to quickly adapt to the dynamic changes of this network topology.

2.1.3. Data-Centric Network. An information network may directly report to a network node user after a node user needs to obtain a certain basic geographic information about an event of a specified network node. This kind of network usage behavior thought that the specific network node data itself is directly delivered as information clues for query or the network transmission node information is indirectly delivered as clues are more on a behavioral habit that is close to natural language or information network communication. 


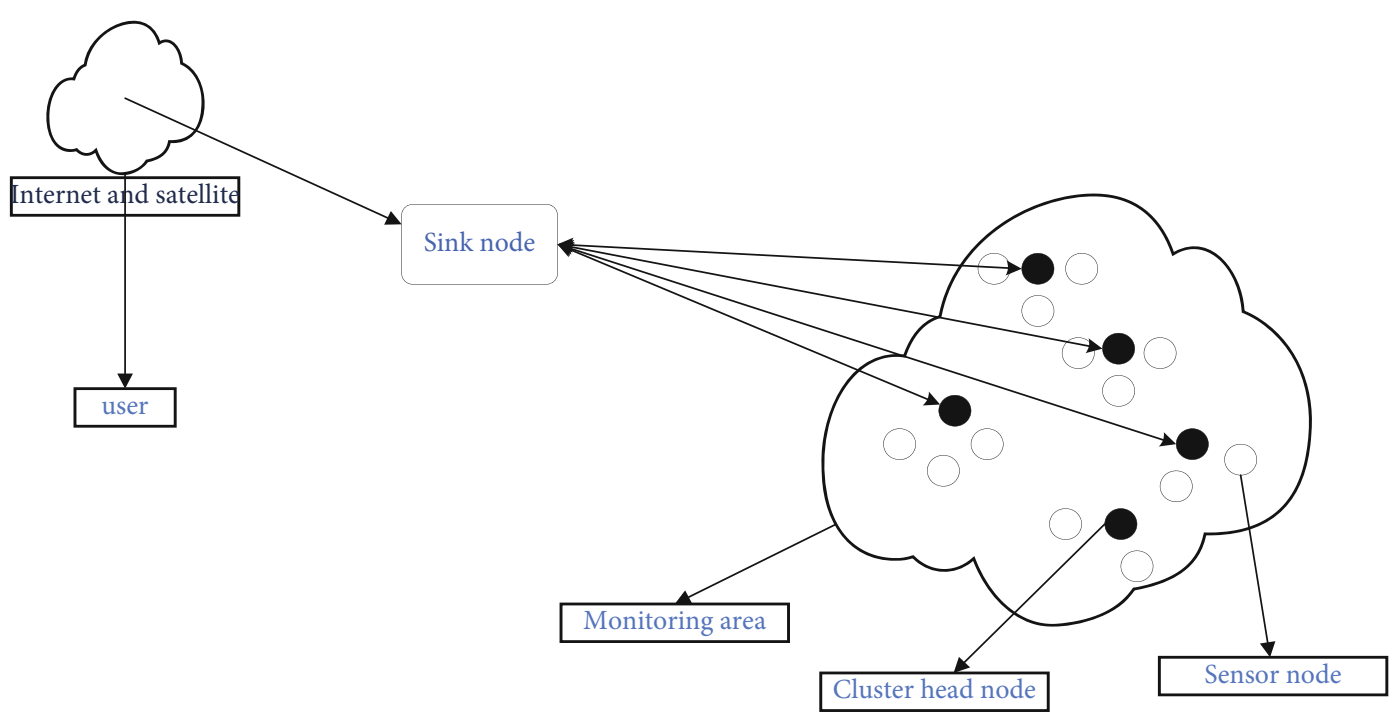

FIgURE 1: Wireless sensor network architecture.

So the usual network sensor that we are talking about is a natural information network that uses the specific network node data itself as the information clue query center. The comparison results of the characteristics of the three fusion methods are shown in Table 1.

2.2. Overview of Data Mining. Data mining is generally called enterprise data resource exploration and data mining. It refers to an important step in the knowledge information discovery process of enterprise database systems. Specifically, it refers to a large amount of knowledge data. Through the use of corresponding MAs, timely and accurate search and mining are performed to find valuable knowledge information that has been hidden or may have been hidden in the entire data resource information system. In actual commercial data applications, data analysis, and processing algorithms for data model information analysis and mining, common data models mainly include four types of data analysis algorithms, classification and periodic data sequence prediction, clustering, association classes and data sequence rules, time table, and periodic data sequence. This article will focus on detailing how to choose the decision tree model as the four analysis methods of the enterprise classification data tree $[12,13]$.

In this mining process, enterprise data needs to fully consider what exactly the enterprise needs to do at each key link and each stage of the mining process, specify each detail of the mining process, and specify each detail process, for example, what to mine data, how much massive data needs to be mined accurately, what data needs to be mined and to what extent, and which data key basic knowledge or key factors need to be accurately extracted as indicators in the entire process of data mining. Therefore, the preliminary data mining work can be summarized into two main levels. One is the selection of enterprise data objects and model determination, and the other is accurate and integrated processing. The purpose is to collect data that needs to be mined. The enterprise
TABle 1: Comparison of different levels of integration.

\begin{tabular}{|c|c|c|c|}
\hline Characteristic & $\begin{array}{l}\text { Pixel-level } \\
\text { fusion }\end{array}$ & $\begin{array}{l}\text { Feature-level } \\
\text { fusion }\end{array}$ & $\begin{array}{l}\text { Decision-level } \\
\text { fusion }\end{array}$ \\
\hline Traffic & Maximum & Medium & The smallest \\
\hline $\begin{array}{l}\text { Fault } \\
\text { tolerance }\end{array}$ & Worst & Medium & Most \\
\hline $\begin{array}{l}\text { Anti- } \\
\text { interference }\end{array}$ & Worst & Medium & Most \\
\hline
\end{tabular}

data model is processed through various groupings, so that the mining efficiency can be optimized to the maximum, and finally the actual performance and effect of the enterprise mining data model can be simplified to the maximum. The model is shown in Figure 2.

2.3. Theoretical Analysis of Financial Early Warning. The theory of early warning of corporate financial crisis is a comprehensive theory that includes multiple discipline. It is a multidisciplinary knowledge covering enterprise risk management, industrial process control, dynamic information technology, mathematical modeling, and so on. The research on the early warning of corporate financial crisis is very similar to the research on mining highly trustworthy rules in intelligent industrial control systems. The early-warning indicators of financial crisis are equivalent to the equipment in the industrial control system. When the indicators fluctuate, they are equivalent to the operating attitude of the industrial equipment. In the event of instability and the fluctuation of financial indicators beyond a certain range, the system should issue an early warning $[14,15]$.

According to the management structure, the various links of enterprise risk management can be designed as shown in Figure 3.

Data mining must first clean up the data, remove the abnormal data, then select and integrate the data, and then transform the data into a type suitable for data mining 

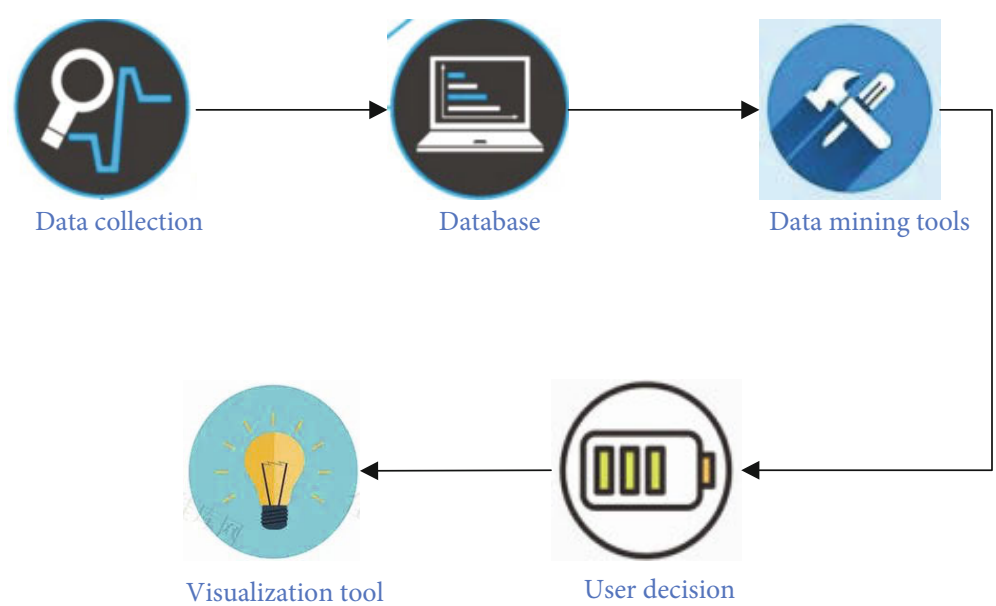

FIGURE 2: Data mining environment.

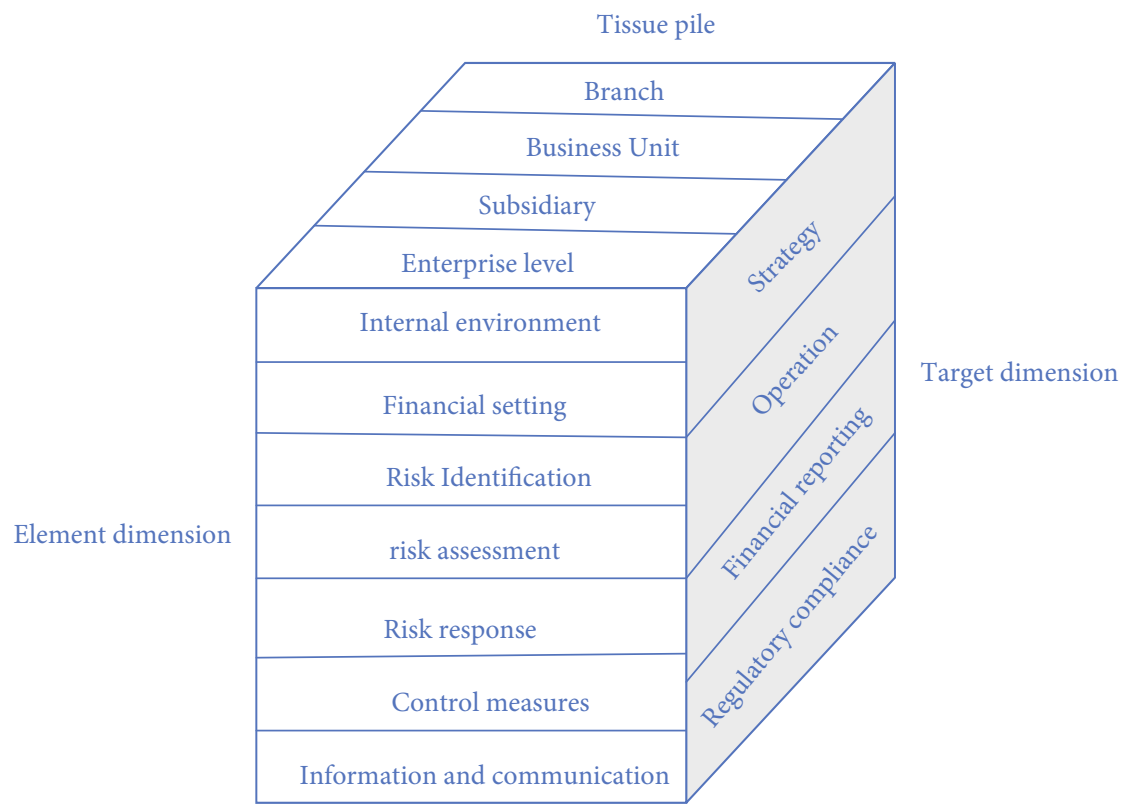

FIGURE 3: Enterprise risk management-integrated framework.

through data transformation. The most important step is to choose a suitable data mining method to find the data. Finally, the hidden patterns and laws in the data are displayed through pattern evaluation and knowledge representation. The methods of data mining mainly include the following:

(1) Classification and Prediction. Classification mining is a method of distinguishing a large amount of data according to the established model. The data can be divided into multiple categories; prediction is to establish a continuous value function model to determine the development trend of future data. This is a method of making predictions.

(2) Clustering. Clustering mining is based on a set of data objects to be analyzed and automatically aggregates into different categories according to the similarity of the instance attribute values.
(3) Association Rules. Association rule mining is used to discover useful or meaningful connections hidden in transaction data sets or relational data sets for users.

(4) Time-Series. Time-series mining is a method of mining sequence objects of values or events obtained by repeated measurements at different times, and it is expected to analyze the trend changes of the data.

Other methods include the following: mining complex data types such as graphics, images, videos, and Web [16, 17]. The refinement of financial management objectives refers to the specific refinement of corporate financial objectives. The specific financial objectives of financial management generally include the specific objectives of corporate monetary fund income management, the specific objectives of cost and income management, the objectives of credit policies, and the improvement of the quality of financial reports. The goals, etc., are shown in Table 2: 
TABLE 2: List of financial target items.

\begin{tabular}{lcc}
\hline Project & \multicolumn{2}{c}{ Merge } \\
& $\begin{array}{c}\text { Number of current } \\
\text { period }\end{array}$ & $\begin{array}{c}\text { Same period last } \\
\text { year }\end{array}$ \\
\hline $\begin{array}{l}\text { Main operating } \\
\text { profit }\end{array}$ & $* * *$ & $* * *$ \\
Operating profit & $* * *$ & $* * *$ \\
$\begin{array}{l}\text { Total profit } \\
\text { Main business }\end{array}$ & $* * *$ & $* * *$ \\
income & $* * *$ & $* * *$ \\
\hline
\end{tabular}

The financial operation risk automatic identification system is an important foundation for strengthening the enterprise financial operation risk management. The identification of risks is also after the enterprise has determined the relevant financial goals, using various methods to analyze the internal and external destruction events that affect the realization of the enterprise's financial goals. The working method of financial customer risk information identification is mainly through various channels and various technical means to collect and obtain sufficient and true customer financial risk information in a timely manner and to organize, classify, and analyze these financial information data in a timely manner. To make a preliminary judgment on the risk of uncertainty, the financial trend chart of a company in recent years is shown in Figure 4.

\section{Simulation and Construction of Financial Management Early Warning}

3.1. MA of Association Rules. Association rule data mining technology is one of the main application technologies for big data analysis and mining. Improving the efficiency of association rule mining is a hot topic. The existing various associated data rule pattern mining and maintenance algorithms mainly refer to some interactive static pattern mining and maintenance methods. When the scanning database changes or the threshold between data support and data confidence is slightly adjusted, it is always possible. There is a problem when the database and the holding degree are repeatedly calculated after multiple holding scans. Aiming at the problem of dynamic maintenance and mining of various associated data rules after the scanning database and holding thresholds are changed, this article mainly proposes a method based on associated data rules. For a dynamic pattern maintenance MA, it is first necessary to study an interactive pattern mining maintenance algorithm for associated data rules. The flowchart of financial crisis early warning is shown in Figure 5.

For the MA, IUA is mainly used here for detailed description [18, 19]. The IUA algorithm is expressed as follows:

$$
\begin{gathered}
e(k)=y(k)-y_{m}(k), \\
E(k)=\frac{1}{2} e^{2}(k) .
\end{gathered}
$$

Here, the input contribution is defined as the product of the input growth rate and its two-period average value share. $A x=X-x t-1$ represents the change from $t-1$ to $t$, and $v$ is equal to the average share of input in the two periods of output. Define the share of each input value as follows:

$$
\begin{aligned}
\alpha & =M^{+} T \\
\operatorname{minLPELM} & =\frac{1}{2}\|\alpha\|^{2}+C \frac{1}{2} \sum_{i=1}^{n}\left\|\gamma_{i}\right\|^{2}, \\
h\left(x_{i}\right) \alpha & =t_{i}^{T}-\gamma_{i}^{T}, i=1, \cdots \cdots n \\
\alpha & =H^{T}\left(\frac{I}{C}+\mathrm{HH}^{T}\right)^{-1} T .
\end{aligned}
$$

This formula was expanded. They divided diversification into interindustry diversification and intraindustry diversification and used EUD (end-user development) to express the degree of interindustry diversification:

$$
\begin{gathered}
\begin{array}{c}
w=1, F(F \in[0,1]), \\
F \in(0.5,1), \\
F=1-\gamma \mathrm{e}-\left|\frac{\mathrm{C}}{C \text { total }}\right|, \gamma \in R+, \\
F=\gamma \mathrm{e}-\left|1-\frac{\mathrm{C}}{\text { Ctotal }}\right|, \gamma \in R+.
\end{array}
\end{gathered}
$$

Since there is currently no statistical data on fixed asset storage locations at the service industry level, the method we adopted is to first use the perpetual inventory method to calculate the total capital stock of the tertiary industry in each year.

$$
\begin{aligned}
E\left[T_{i}\right] & =P_{m}^{i} * P_{r} W_{i-1}, \\
E\left[T_{i}\right] & =\sum_{i=0}^{M C} E\left[T_{i}\right], \\
\operatorname{Max} E & =\operatorname{fix}\left(\log _{2}(N)\right) K=\operatorname{fix}\left(\log _{2}\left(\frac{N}{2}\right)\right) .
\end{aligned}
$$

Then, use the ratio of fixed asset investment in each industry to the fixed asset investment in the tertiary industry to estimate the industrial fixed capital stock, which is the following:

$$
\begin{aligned}
\Delta w_{i j}^{I}(k) & =-\frac{\partial E(k)}{\partial w_{i j}^{I}}=e(k) \frac{\partial y_{m}}{\partial X_{j}} \frac{\partial X_{j}}{\partial w_{i j}^{I}}, \\
e(k) \frac{\partial y_{m}}{\partial X_{j}} \frac{\partial X_{j}}{\partial w_{i j}^{I}} & =e(k) w_{j}^{O} Q_{j}(k) .
\end{aligned}
$$

Regarding the selection of the specific production function, Jorgensen decomposed the output growth into the contribution of each input and the remaining total factor 


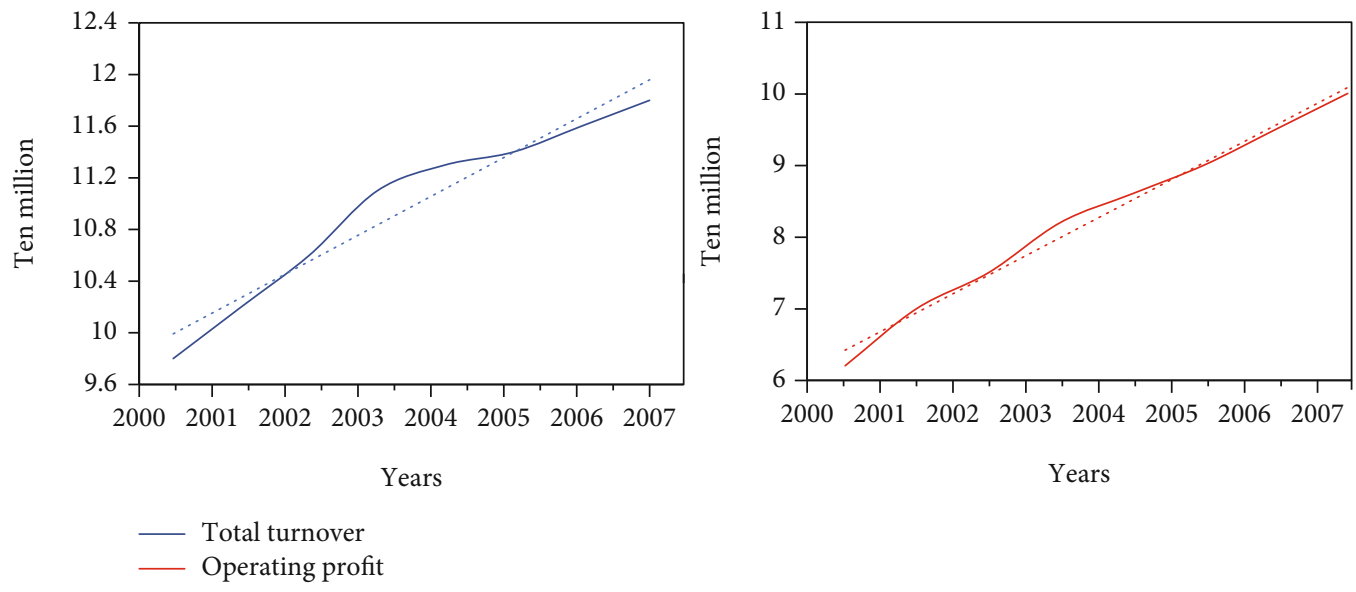

FIGURE 4: The company's turnover curve of a company in recent years.

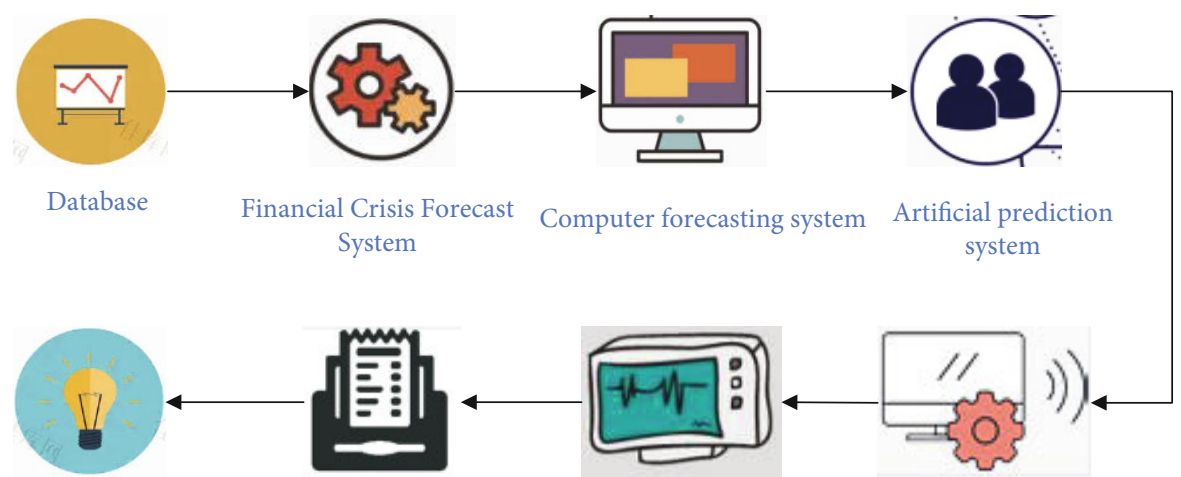

Financial Crisis Forecast Financial crisis information Financial Crisis Forecast Financial Crisis Pretreatment Team

release System

System

FIgURE 5: Flowchart of financial crisis warning.

productivity according to the standard growth calculation formula:

$$
\begin{gathered}
w_{i j}^{I}(k)=w_{i j}^{I}(k-1)+\mu \Delta w_{i j}^{I}(k), \\
x(t)=2 \sum_{k=1}^{N / 2-1}\left|C_{K}\right| \cos \left(k w_{0} t+\beta_{k}\right), \\
x(t)=2 \sum_{k=1}^{N / 2-1} a_{k} \cos \left(k w_{0} t\right)+b_{n} \sin \left(k w_{0} t\right) .
\end{gathered}
$$

According to the idea of multiple linear regression, the autoregressive moving average model ARMA ( $n$ and $m$ ) can be generally expressed as follows:

$$
x_{t}=\alpha_{t}-\sum_{j=1}^{m} \theta_{j} \alpha_{t-j},
$$

in

$$
\alpha_{t} \sim \operatorname{NID}\left(0, \delta_{a}^{2}\right) .
$$

In the process of research and construction of the financial early-warning risk model, it is necessary to accurately grasp the risks in the financial management of the risk control company and the functions in the earlywarning system, such as the risk forecast function, the risk diagnosis function, the risk control function, and the health management function. The so-called risk prediction and diagnosis function, for a listed company, tracks a listed company's own production, operation, and management process and synchronizes with the listed company's own scheduled business goals based on the actual progress of the listed company's own production, operation, and operation. It is possible to accurately match each other. In-depth research and analysis of listed companies themselves in terms of production and operation management may also occur; at the same time, some risk issues and financial risk predictions are made. The correlation analysis is shown in Table 3.

Through correlation analysis, it is possible to find out the various factors that really affect the financial risk status of the enterprise more accurately and to find the problem in time through comparison with peers. For example, the company's internal financial information is analyzed under the association rule interactive mining strategy, and different support thresholds and confidence thresholds are set 
according to the actual situation of the company and the industry, which can more accurately find abnormalities in financial indicators.

\subsection{Financial Management Early-Warning Model Based on} Data Mining. Use different correlation cost rule interactive cost mining analysis algorithm to interactively mine the main financial potential risks and index costs of Chinese companies, and find the correlation rules between different financial index cost systems and in-depth analysis of the real reasons for the potential financial risks of Chinese companies. The root cause lays the foundation for enterprises to get rid of the influence of financial risks $[20,21]$.

\subsubsection{Construction of Risk Concept Hierarchical Tree. A key} means to establish a set of corporate financial indicator risk analysis model is to build a multilevel structure tree of financial risk analysis concepts based on the corporate financial indicator analysis system model. The financial indicator analysis system mainly includes the actual profitability, operation, growth, and compensation of an enterprise. Risk analysis has five aspects of debt business capability and corporate cash flow, each of which contains different concepts of financial indicators. In the tree in the financial concept data hierarchy, using the concept generic replacement of the high concept hierarchy tree and the middle and level concepts can effectively realize the hierarchical generic transformation of financial data. The tree in the corporate financial data risk management concept data hierarchy can be divided into four layers according to the structure, which are conceptual levels $0,1,2$, and 3 . Level 0 is the highest level of the tree, and the top level of the hierarchical tree is marked according to the connection points. It refers to the level of corporate financial risk. Level 1 is the second level, which refers to the five aspects of corporate financial risks, and level 2 is the third level, which includes comprehensive key indicators of corporate financial risks. The specific content includes the following: profit rate, return on investment, and liquidity asset turnover rate $[22,23]$. Level 3 is the lowest level. Figure 6 is the hierarchical tree structure of the corporate financial risk concept.

\subsubsection{Interactive Mining Strategy with Decreasing Support} Threshold. The interactive data mining calculation strategy of decreasing the risk support range threshold also means that each level of the data tree based on the risk support hierarchy needs to correspond to a minimum risk support flow threshold [24, 25]. The lower the financial index at this level and the corresponding minimum risk, the lower the threshold for supporting flow. For example, as shown in the figure above and below, the minimum risk support flow threshold value of the first and second levels is $20 \%$, and the minimum risk support flow threshold value of the second and third levels is $10 \%$. Figure 7 is an interactive data mining calculation strategy based on the decreasing risk support range threshold.

When considering the minimum support for the association rules between different levels, it should be determined according to the minimum support of the lower level.
TABle 3: Association analysis.

\begin{tabular}{lcccc}
\hline $\begin{array}{l}\text { Financial } \\
\text { indicator }\end{array}$ & $\begin{array}{c}\text { Current } \\
\text { ratio }\end{array}$ & $\begin{array}{c}\text { Inventory } \\
\text { turnover }\end{array}$ & $\begin{array}{c}\text { Assets and } \\
\text { liabilities }\end{array}$ & $\begin{array}{c}\text { Net sales } \\
\text { profit margin }\end{array}$ \\
\hline $\begin{array}{l}\text { Strong } \\
\text { association }\end{array}$ & $\leq 1.6$ & $\leq 2.4$ & $\geq 58 \%$ & $\leq 6 \%$ \\
rules & & & & \\
Support & $70 \%$ & $65 \%$ & $58 \%$ & $80 \%$ \\
Confidence & $55 \%$ & $75 \%$ & $66 \%$ & $60 \%$ \\
\hline
\end{tabular}

3.2.3. Data Mining and Result Output. Use the interactive MA of association rules to mine the enterprise financial risk hierarchical tree layer by layer, adjust the support threshold for different levels of mining according to the user's requirements, and finally get the result that the user is satisfied with.

3.3. Experimental Simulation of Financial Management Early Warning. Through long-term empirical analysis and research, we can test the scientific validity of China's financial crisis monitoring and early-warning processing index system and establish and construct an effective set of China's dynamic long-term financial crisis based on China's financial crisis monitoring and early-warning indicator model and crisis early-warning processing procedures, monitoring, and early-warning system. One is unilateral. For listed companies that have experienced continuous major financial crises, long-term empirical analysis can be used to find the main source that may affect the further aggravation and deterioration of listed companies' financial asset crises. On the other hand, we can comprehensively use the public financial data of many existing listed companies in China to predict the next listed company that is most likely to continue to have a major financial crisis this year and provide corporate managers with auxiliary decision-making support for corporate development strategies. It can also provide a basis for investors' investment decisions [26].

The cleaning of sample data is to eliminate outliers of all variables, because the existence of outliers will affect our descriptive analysis of enterprise financial crisis early warning and cause great deviations. Therefore, before discretizing and reconstructing the sample data, we analyzed all the values of each variable and eliminated the abnormal data. The purpose of database reconstruction is to discretize the continuous data of financial crisis warning indicators and transform them into discrete financial indicator data suitable for mining association rules. Since the distribution of each financial indicator variable in the data set composed of financial data of different companies is basically a normal distribution, we choose to use the normal distribution and other area division methods to discretize continuous variables. In this chapter, according to the distribution of each variable, the $1 / 5,2 / 5,3 / 5$, and $4 / 5$ points of the function discretize each financial indicator variable into 5 levels. Table 4 is the database.

The key to establishing a corporate financial risk analysis model is to build a risk concept hierarchy tree based on the financial indicator system. The financial indicator 


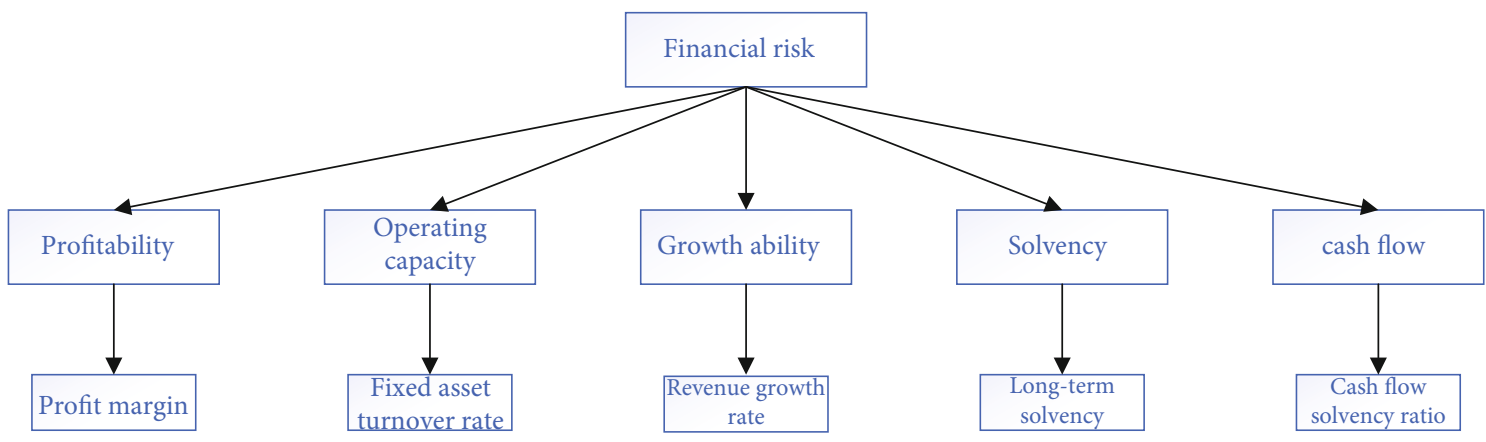

FIgURE 6: Hierarchical tree structure diagram of corporate financial risk concept.

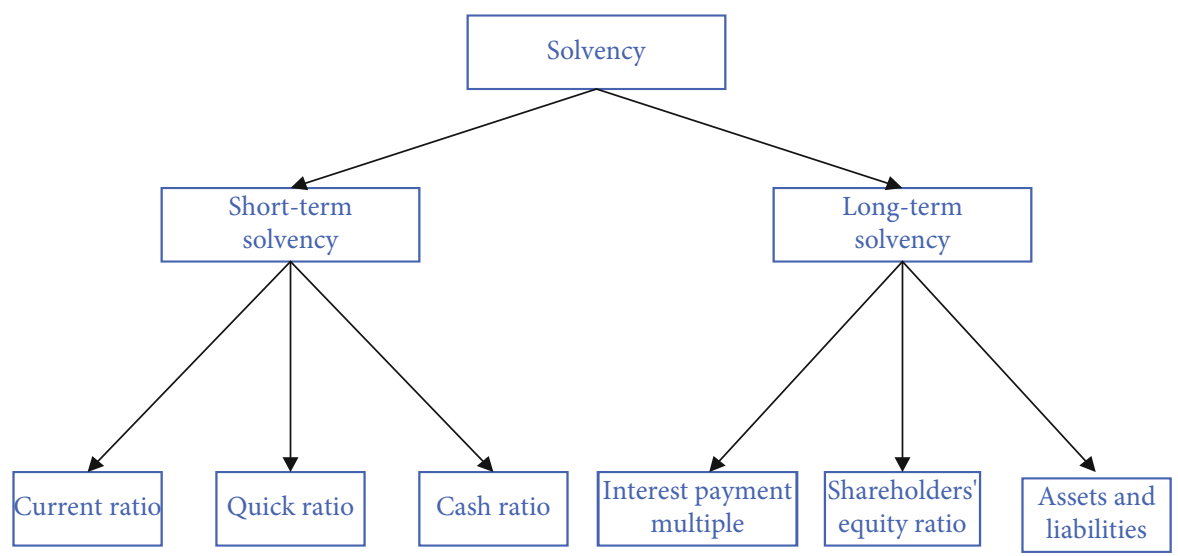

FIGURE 7: Interactive mining strategy with decreasing support threshold.

system includes analysis of the company's profitability, operation, growth, solvency, and cash flow. Each module includes different financial indicator concepts. In the concept hierarchy tree, the generalization of the data can be achieved by replacing the low-level concepts with highlevel concepts. The hierarchical tree structure of the financial risk concept is divided into four levels, namely, levels $0,1,2$. and 3. Level 0 is the highest level and is the root node mark of the tree, which refers to the level of corporate financial risk. Level 1 is the second level, which refers to the five aspects of corporate financial risks, and level 2 is the third level, which includes comprehensive key indicators of corporate financial risks. The specific content includes the following: profitability, return on investment, and liquidity asset turnover. Level 3 is the lowest level and is the index level that describes the most specific concept of financial risk. The specific content includes the following: gross profit margin, net profit margin, earnings per share, and account receivable turnover rate. According to the requirements of modern corporate governance structure and equity structure, corresponding auxiliary financial indicators have been added, such as the actual controller of the listed company, the shareholding ratio of major shareholders, CR3 index, $\mathrm{Z}$ index, and corporate management structure indicators in the corporate equity structure indicators. Figure 8 shows the number of board members in the board, and the proportion of board shares were held in the board, etc..
A new type of enterprise financial asset crisis information early-warning data model is dynamically analyzed and maintained according to the mining time rule sequence. Frequent data mining of relevant financial index data in the past period of time can be performed frequently to mine the first excavation time and node-related finances. The data will then be added and mined based on the subsequent mining time and the relevant financial data of the node, and then, the financial incremental data mining will be carried out. In addition, it is also possible to set different data support benchmark thresholds and different confidence benchmark thresholds, make comprehensive adjustments to the data mining results you want, find a number of frequent mining patterns and time rule values that meet the requirements of the enterprise financial crisis data early-warning model indicators, and comprehensively analyze the final data mining results.

\section{Experimental Results and Analysis}

4.1. Anticipating a Financial Crisis. The financial crisis of an enterprise is an evolving process for a period of time. It is a concept of a period. There is a crisis from the initial stage to the gradual deterioration and finally to the stage of corporate bankruptcy. After empirical research and rule screening, this article proposes a combination of qualitative analysis and quantitative analysis to determine the degree of corporate crisis and different stages. Qualitative analysis is to judge 
TABle 4: A company's original financial database.

\begin{tabular}{lcccccc}
\hline Stock code & Stock name & Earnings per share & Cash flow per share & Roe & Net interest rate & Account receivable turnover rate \\
\hline 000595 & *ST west axis & -0.1 & 0.34 & -10.25 & -27.66 & 0.25 \\
000607 & *ST Huakong & -0.2 & -0.58 & -11.23 & -0.55 & 0.67 \\
001542 & *ST Tianrun & -0.05 & 0.65 & -6.89 & -10.65 & 4.58 \\
001285 & *ST Furi & -0.11 & 0.25 & -5.23 & -3.65 & 3.25 \\
\hline
\end{tabular}
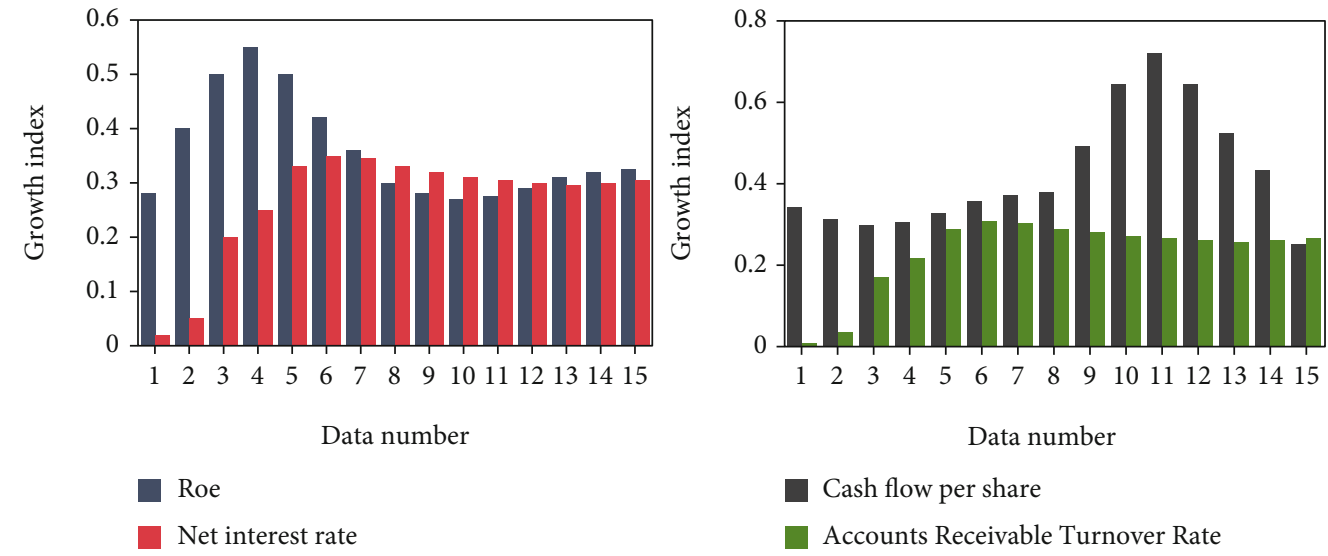

Figure 8: A graph of various financial data of a certain company.
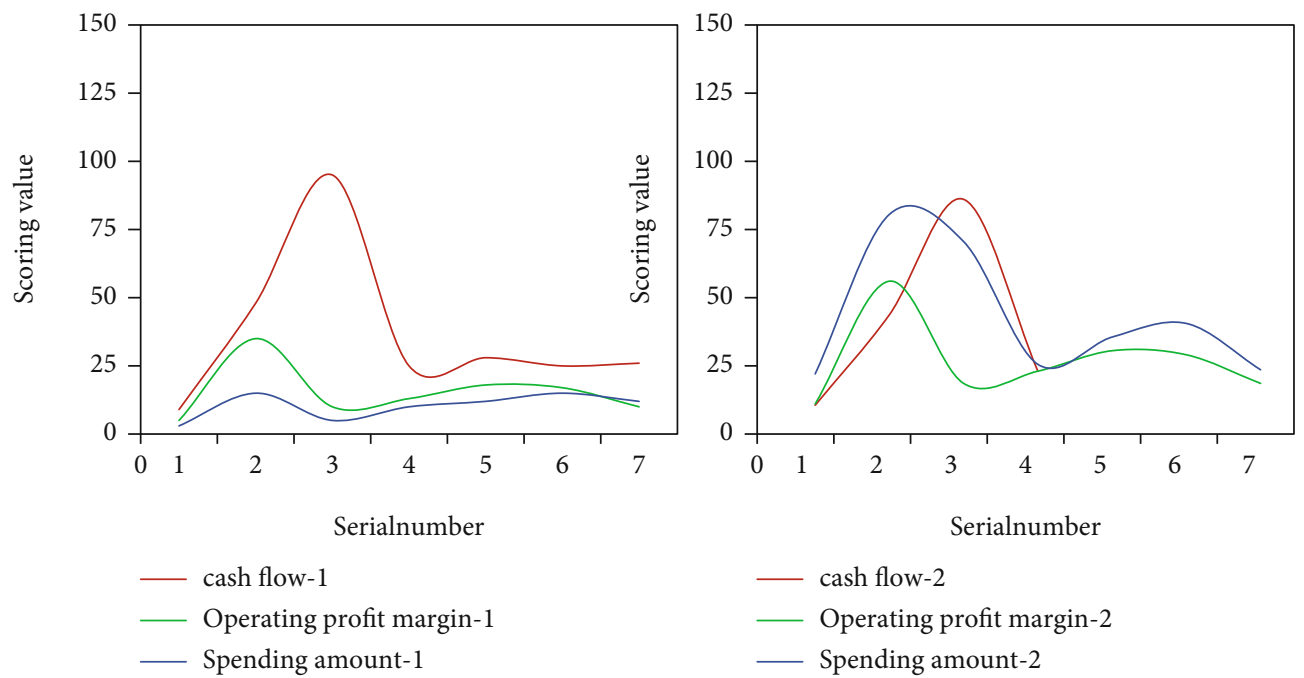

FIgURE 9: A company's financial early-warning trend chart.

the degree of crisis of the enterprise according to the development trend of the rules; quantitative analysis is to finally determine the crisis stage of the enterprise by calculating the crisis coefficient. The financial forecast of the company is shown in Figure 9.

\subsubsection{Qualitative Analysis Method}

(1) If the rule is low in the antecedent and high in the latter, then the corporate crisis will be aggravated; conversely, if the antecedent is high and the latter is low, the corporate crisis will be alleviated
(2) If the rules are always at level 1 , the degree of corporate crisis is relatively light. If the rules are always at the level of 3 , the degree of corporate crisis is moderate. If the rules are always at the level of 5, the company is on the verge of bankruptcy

(3) If the regular distribution is relatively scattered, then the method of quantitative analysis is adopted

4.1.2. Quantitative Analysis Method. The comprehensive factor method is used to calculate the crisis coefficient, and the crisis coefficient formula is used to calculate the specific degree of the corporate financial crisis. 

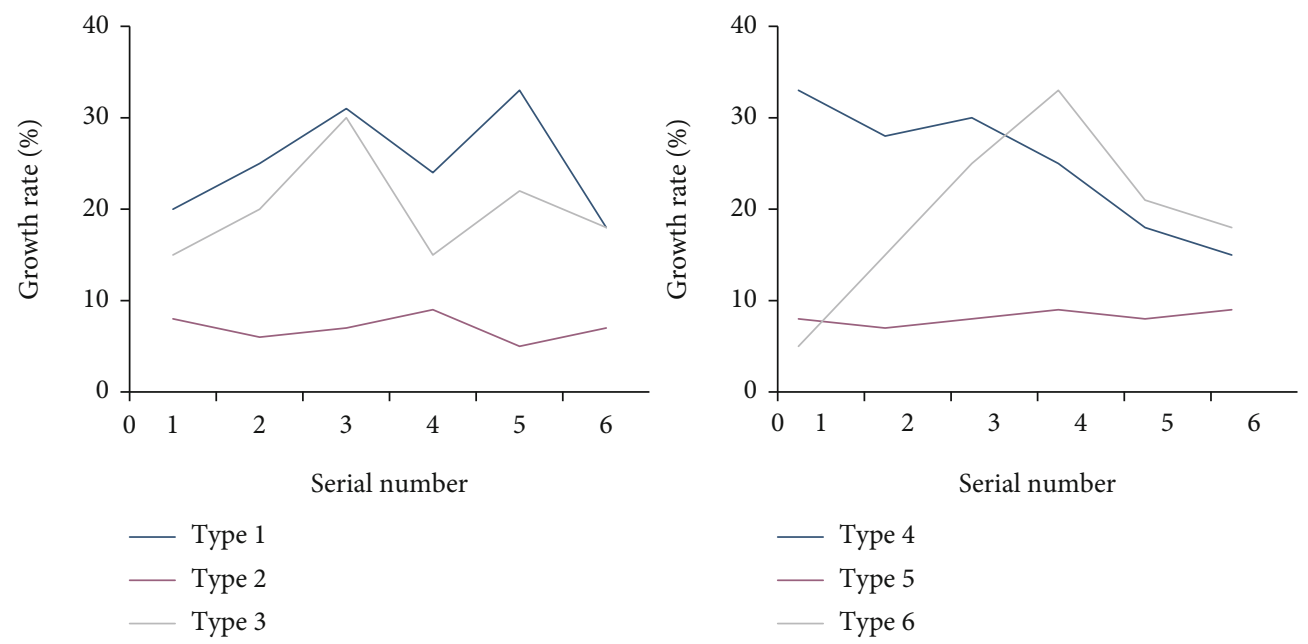

Figure 10: Six typical financial development trends.

In this case, the relevant personnel will determine the specific interpretation and evaluation methods based on the success or failure of the mining operation results. However, in the process of using data, analysts will want to be able to evaluate the results in order to make the data successful in the process. In the process of mining data, relevant personnel need to consider the following issues: the operating model is better than the model on the data set; the accuracy of the model is better than the accuracy of other models; the model is mainly based on the sample model, but the actual process will be far behind the mold time.

Through the comprehensive analysis of big data with interrelated rules, some large companies have realized the analysis and classification of the data obtained in the current actual test by comparing the big data with their counterparts in other industries. Highly improve the practical application, importance, and feasibility of the entire enterprise financial risk early-warning system in the analysis of data classification of the entire enterprise's financial index status information and the enterprise's financial index decision-making risk management.

4.2. Decision-Making Suggestions for Predicting Financial Crisis. This article selects six types of corporate development trends for research, mainly include the following: two years of profit after the first year of loss; two years of loss in the first two years of profit in the third year; loss of the first two years of loss in the third year; two years after the first year of profit; annual loss, profit in the first two years, loss in the third year, profit in the first two years, and profit in the third year. Generally, it can be classified into two types of trends, namely, from loss to profit and from profit to loss. The focus is on the future development and change trend of the company's losses, and the development trend chart is shown in Figure 10.

It can be seen that the company's current ratio, inventory turnover ratio, asset-liability ratio, and net sales profit are higher, and the thresholds of support and confidence are higher than $50 \%$, indicating that the company's various financial indicators have a strong correlation with each other. Based on the data results tested, relevant personnel can make further corresponding decisions based on the success or failure of the mining operation results and give specific explanations and evaluations. According to the actual financial indicators of various industry companies and companies in different financial industries, setting different comparison values on the threshold comparison value of the entire enterprise financial support data index table and the entire enterprise financial confidence data index threshold can be more accurate. Timely discover the abnormal situation of various financial indicators in the process of analyzing the financial status indicator information of the entire enterprise. For the staff of the company's financial department, the next step is to dig and analyze. The financial early-warning model itself, which is the operating model used in this data test, explores and analyzes whether it is truly superior to the model on the data set. It needs to be analyzed from the test results whether the accuracy of this model is better than other models, and its prediction accuracy rate of financial crisis reached $62.35 \%$.

\section{Conclusion}

With the rapid development of China's capital market, enterprises are facing a fierce market competition environment, and strengthening enterprise risk management has become a topic that modern enterprises must face. This paper proposes a financial management analysis method based on wireless sensor networks and data mining and a financial crisis early-warning method based on time series dynamic maintenance. It actively explores the key factors affecting corporate financial risks, and according to the trend of changes in financial indicators, it is the company's possible financial early-warning of the crisis. It is proposed to apply association rule interactive MA (methanandamide) to enterprise financial risk analysis. This article mainly discusses the use of a financial research theory method of interactive cross-comprehensive data mining by associating multiple financial management rules, selecting a wider range of important related financial indicators in related financial 
management, and comprehensively mining all related financial indicators through interaction. Based on various related financial rules, we can finally determine how to comprehensively select more and a certain international and representative important financial indicator as a risk assessment financial indicator, which is more objective than traditional analysis methods. Real application significance: when data mining correctly analyzes corporate financial data risks, it will go through the following main steps: data mining analysis object, data analysis preparation, establishment of analysis model, data comprehensive mining, and result data analysis. Only by doing the work of these stages correctly can the financial risks be accurately applied. In short, the establishment of a financial early-warning system can provide more unpredictability to the company's investor management and always guide the company's financial department to make more scientific and feasible project management decisions. For all employees of the company's financial department, the most important point is to be able to reflect and present relevant information about the company's true existence value in a timely manner, so that the company's senior leaders and other investors can receive early information about the company's potential important warning of financial crisis. However, this article still has some algorithm flaws. Data mining methods can be further studied to improve the efficiency of data mining to meet the needs of large-scale database mining.

\section{Data Availability}

No data were used to support this study.

\section{Conflicts of Interest}

The authors declare that they have no competing interests.

\section{References}

[1] A. Buczak and E. Guven, "A survey of data mining and machine learning methods for cyber security intrusion detection," IEEE Communications Surveys \& Tutorials, vol. 18, no. 2, pp. 1153-1176, 2016.

[2] C. Helma, T. Cramer, S. Kramer, and L. De Raedt, "Data mining and machine learning techniques for the identification of mutagenicity inducing substructures and structure activity relationships of noncongeneric compounds," Journal of Chemical Information and Computer Sciences, vol. 35, no. 4, pp. 1402-1411, 2004.

[3] W. Duivesteijn, A. J. Feelders, and A. Knobbe, "Exceptional model mining," Data Mining and Knowledge Discovery, vol. 30, no. 1, pp. 47-98, 2016.

[4] D. A. Adeniyi, Z. Wei, and Y. Yongquan, "Automated web usage data mining and recommendation system using $\mathrm{K}$ Nearest Neighbor (KNN) classification method," Applied Computing \& Informatics, vol. 12, no. 1, pp. 90-108, 2016.

[5] P. Wang, "Survey on privacy preserving data mining," International Journal of Computer Science \& Information Technology, vol. 24, no. 9, pp. 1-7, 2017.
[6] E. Lin, E. W. Sun, and M. T. Yu, "Systemic risk, financial markets, and performance of financial institutions," Annals of Operations Research, vol. 262, no. 2, pp. 579-603, 2018.

[7] N. Purves, S. Niblock, and K. Sloan, "Are organizations destined to fail?," Management Research Review, vol. 39, no. 1, pp. 62-81, 2016.

[8] D. Vidal-Tomas and S. Alfarano, "An agent-based early warning indicator for financial market instability," Journal of Economic Interaction and Coordination, vol. 15, no. 1, pp. 4987, 2020.

[9] Q. Wang, F. Hui, X. Wang, and Q. Ding, "Research on early warning and monitoring algorithm of financial crisis based on fuzzy cognitive map," Cluster Computing, vol. 22, no. S2, pp. 3689-3697, 2019.

[10] "'Construction of supply chain financial risk management mode based on Internet of Things, " in IEEE," Access, vol. 7, pp. 110323-110332, 2019.

[11] M. N. Shad, M. Maadani, and M. N. Moghadam, "GAPSOSVM: an IDSS-based energy-aware clustering routing algorithm for IoT perception layer," Wireless Personal Communications, pp. 1-20, 2021.

[12] "Application of data mining technology in financial risk analysis," Wireless Personal Communications, vol. 102, no. 4, pp. 3699-3713, 2018.

[13] "Embedded microprocessor wireless communication data collection aids in early warning of default risk for internet finance bank customers," Journal of Sensors, vol. 2021, 10 pages, 2021.

[14] L. Piciullo, M. P. Dahl, G. Devoli, H. Colleuille, and M. Calvello, "Adapting the EDuMaP method to test the performance of the Norwegian early warning system for weather-induced landslides," Natural Hazards and Earth System Sciences, vol. 17, no. 6, pp. 817-831, 2017.

[15] Q. Qiao and P. A. Beling, "Decision analytics and machine learning in economic and financial systems," Environment Systems \& Decisions, vol. 36, no. 2, pp. 109-113, 2016.

[16] J. L. Koposko and D. A. Hershey, "When I first learned about retirement: financial and retirement concept recognition among college students," Current Psychology, vol. 35, no. 4, pp. 540-548, 2016.

[17] B. G. Chae, H. J. Park, F. Catani, A. Simoni, and M. Berti, "Landslide prediction, monitoring and early warning: a concise review of state-of-the-art," Geosciences Journal, vol. 21, no. 6, pp. 1033-1070, 2017.

[18] W. Dai, Y. Dong, and X. Zhang, "Competitive analysis of the online financial lease problem," European Journal of Operational Research, vol. 250, no. 3, pp. 865-873, 2016.

[19] A. Cano and J. D. Leonard, "Interpretable multi-view early warning system adapted to underrepresented student populations," IEEE Transactions on Learning Technologies, vol. 12, no. 2, pp. 198-211, 2019.

[20] G. Smith and N. Juria, "Diagnosis of historical inundation events in the Marshall Islands to assist early warning systems," Natural Hazards, vol. 99, no. 1, pp. 189-216, 2019.

[21] A. Forkan, I. Khalil, A. Ibaida, and Z. Tari, "BDCaM: big data for context-aware monitoring-a personalized knowledge discovery framework for assisted healthcare. IEEE Transactions on Cloud," Computing, vol. 5, no. 4, pp. 628-641, 2017.

[22] S. Say, H. Inata, J. Liu, and S. Shimamoto, "Priority-based data gathering framework in UAV-assisted wireless sensor networks," IEEE Sensors Journal, vol. 16, no. 14, pp. 5785-5794, 2016. 
[23] L. M. Candanedo, V. Feldheim, and D. Deramaix, "Data driven prediction models of energy use of appliances in a low-energy house," Energy and Buildings, vol. 140, no. APR., pp. 81-97, 2017.

[24] G. N. Pradhan and B. Prabhakaran, "Association rule mining in multiple, multidimensional time series medical data," Journal of Healthcare Informatics Research, vol. 1, no. 1, pp. 92118, 2017.

[25] C. J. Deepu, C. H. Heng, and Y. Lian, "A hybrid data compression scheme for power reduction in wireless sensors for IoT," IEEE Transactions on Biomedical Circuits and Systems, vol. 11, pp. 245-254, 2017.

[26] S. Wan, Y. Zhang, and J. Chen, "On the construction of data aggregation tree with maximizing lifetime in large-scale wireless sensor networks," IEEE Sensors Journal, vol. 16, no. 20, pp. 7433-7440, 2016. 